\title{
Exploring the Characterization of biodegradable plastic "polyhyroxybutrate" (PHB) from Bacillus siamensis PHB 01 (MW440618) isolated from termite mound soil of Western Ghats of Coimbatore, Tamil Nadu.
}

Subasri Mani ( $\nabla$ subasritnau@gmail.com )

Tamil Nadu Agricultural University https://orcid.org/0000-0003-0799-9366

Gomathi Veu

Kavitha Mary Jackson

Research Article

Keywords: Bacillus spp., PHB, 16S rRNA, FTIR, Soil, XRD

Posted Date: January 7th, 2022

DOI: https://doi.org/10.21203/rs.3.rs-1219172/v1

License: (c) (i) This work is licensed under a Creative Commons Attribution 4.0 International License.

Read Full License 


\section{Abstract}

The present study was aimed to explore the characterization of polyhydroxy butrate extracted from the bacterial strain under optimized conditions for the production of bioplastic. Under optimized fermentation conditions, Polyhydroxy butrate (PHB) was extracted and subjected to examine their properties via Thin Layer Chromotogram (TLC), Gas Chromotogram- Mass Spectrometer (GC-MS), Fourier Transform Infrared spectrum (FTIR). The presence of a brown spot in the TLC plate indicates the presence of hydroxylgroup which is similar to the polymer group. GC-MS analysis of extracted PHB shows peaks at the retention time of $3.8,11.6$ which is corresponding to octadecanoic acid, hexadecanoic acid, butyl -2-ethylester confirms the presence of polymeric nature in the extracted PHB. The absorption bands of FTIR at 1719$1720 \mathrm{~cm}-1$ indicate the presence of $\mathrm{C}=0$ group of $\mathrm{PHB}$. The absorption peaks at wave numbers 500$1000 \mathrm{~cm}-1,1055 \mathrm{~cm}-1$ and $1230 \mathrm{~cm}-1$ denotes $(\mathrm{OH})$ group, $(\mathrm{C}-\mathrm{O})$ stretch and $(\mathrm{C}=0)$ ester group. From these results, it was confirmed that the extracted PHB is having the potential to replace petroleum plastic.

\section{Introduction}

Synthetic polymers, "plastic" have become a necessary part of daily life with a wide range of applications in agriculture, household, medicine and packaging. Excessive use of petroleum derived plastic resulted in environmental pollution, since they remained in soil which poses threat to terrestrial and aquatic ecosystems. Most of the plastics available in the market are not easily degradable due to their petroleum nature. There is an urgent need to safeguard our environment from the plastic world in an eco-friendly way. In recent days, the use of biodegradable plastic seeks attention globally. Bio-plastics such as starch derivates, poly lactic acid (PLA), polymeric cellulose, poly hydroxyl alkanoates (PHA) plays a wide role with the added advantage of being produced from renewable resources such as plants and microbial sources. There are many types of biodegradable plastics with different degrees of biodegradability. Among them, polyhydroxybutyrate (PHBs) are the only $100 \%$ biodegradable ones.

PHB is a biodegradable thermoplastic that can be extracted from a wide range of micro-organisms. PHB and its copolymers are members of the PHA family commonly known as best bacterial polyesters produced by a microbial process on enriched sugar medium and act as carbon and energy storage material. PHB synthesis takes place when a suitable carbon source is available in excess amount and cellular growth is limited due to other nutrient limitations. Bio-degradable polymers found to be a promising tool for reducing these global environmental issues.

Microbial PHB shares the common property with petroleum-derived plastics are represented in Table 1. This differentiates PHB from most other currently available biodegradable plastics, which are either water-soluble or moisture sensitive. PHB has good oxygen permeability, ultra-violet resistance but poor resistance to acids and bases. PHB is soluble in chloroform and other chlorinated hydrocarbons and biocompatible and hence it is suitable for medical applications also. Reshma et al. (2017). In reality, advancements in microbial synthesis, industrial-scale production and application are still far. A wide range of microbes was used in the production of PHB, which included bacteria, algae, actinomycetes, 
some molds and yeast. Only a few were reported to accumulate a considerable amount of PHB, among 300 PHB-producing bacterial strains. (Wang, 2013). Both Gram-positive and negative bacteria accumulated PHB. But, Gram-positive Bacillus spp. are considered super microbial factories for commercial production of PHB was reported by Kumar et al.(2009).

Furthermore, the chemical structure of the PHB synthesized by the bacterial isolate was also determined by FTIR spectroscopy analysis.

\section{Materials And Methods}

The bacterial isolate Bacillus siamensis PHB 01 (MW440618) was selected based on the initial and secondary screening (Subasri et al., 2021). Then the potent isolate was subjected to different fermentation conditions such as carbon source, $\mathrm{pH}$, temperature, incubation period and characterized.

\section{Cell cultivation and Extraction of PHB}

For large-scale growth, inoculums were prepared in nutrient broth medium at $37^{\circ} \mathrm{C}$ and transferred to 500 $\mathrm{mL}$ of nutrient broth in a wide-necked $1 \mathrm{~L}$ culture flask, incubated at $37^{\circ} \mathrm{C}$ for $48 \mathrm{~h}$ with continuous gentle shaking. A sample of culture solution $(0.1-0.2 \mathrm{ml})$ was added to $4 \mathrm{ml}$ of the sample were centrifuged for $30 \mathrm{~min}$ to precipitate the solution and then left for $24 \mathrm{~h} .0 .4 \mathrm{ml}$ of the sample was centrifuged for $30 \mathrm{~min}$ to precipitate the PHB. The solid pellet was resuspended and washed with $1 \mathrm{ml}$ portions of water acetone and ether. Chloroform was added and allowed to boil in a water bath at $100^{\circ} \mathrm{C}$. The settled material after evaporation of chloroform was dried at $40^{\circ} \mathrm{C}$ for $30 \mathrm{~min}$. The extracted PHB was subjected to further characterization.

\section{Characterization of PHB}

The chemical structure and the thermal properties of PHB were used as parameters for qualitative analysis of PHB. Characterization and determination of native PHB like granules involved precise measurements to analyze their physical properties and were characterized by TLC, GC- MS, FTIR, XRD.

\section{Thin layer chromatography (TLC)}

A glass plate of $10 \times 5 \mathrm{~cm}^{2}$ size was coated with silica gel of about $3 \mathrm{~g}$ per $15 \mathrm{ml}$ of chloroform. And the prepared solution was spread onto the plate using a spreader (Panda et al., 2008). $1 \mu \mathrm{l}$ of sample (Extracted PHB) was loaded on the TLC plate and allowed to run in the solvent system consisting of 1:1 of ethyl acetate and benzene mixture for $40 \mathrm{~min}$. The plate was left to dry after the run and for staining $50 \mathrm{ml}$ of iodine solution (Hi-media ${ }^{\circledR}$ ) was vaporized in the water bath at 80 to $100^{\circ} \mathrm{C}$. TLC plate was kept over the beaker containing iodine solution for 5-10 min to get it saturated with iodine vapor. The Rf values of the spots were calculated.

\section{GC-MS Analysis}


A solution of $1 \mathrm{ml}$ chloroform, $0.85 \mathrm{ml}$ of methanol and $0.15 \mathrm{ml}$ of sulphuric acid was prepared. This solution was added to about $2 \mathrm{mg}$ of extracted PHB and heated to $100^{\circ} \mathrm{C}$ for 140 minutes. And the analysis was done at the Biocatalysts Laboratory, Department of Agricultural Microbiology.

\section{Fourier Transform Infra Red spectroscopy analysis (FT-IR) of extracted PHB}

FT-IR helps in identifying the chemical structure of the compound under study by finding the required functional groups. The extracted powdered PHB was subjected to IR analysis. The relative intensity of transmitted light was measured against the wavelength of absorption on the region 800 to $4000 \mathrm{~cm}^{-}$

${ }^{1}$ using IR double beam spectrophotometer (Jasco, Japan). IR spectra of samples were measured at ambient conditions.

\section{Results And Discussion}

Climate change and environmental and waste management have turned attention to the development of biodegradable plastics with physical and chemical qualities equivalent to conventional plastics. There has been an increased demand in public as well as scientific research for the development of biodegradable polymers. PHB accumulation as cytoplasmic inclusions in certain bacteria during unbalanced growth conditions has proved to be the best suitable alternative to overcome this problem. More efforts to develop an economically feasible process for the synthesis of PHB should take the center stage most preferably from microbial origin. Based on the properties like biodegradable and nontoxic, it can be used for medical applications also. But the drawback in PHB lies in its cost of production, which is preferably high than petroleum plastic since PHB as it is currently produced cannot handle such high impact.

Many bacteria such as Azotobacter, Bacillus, Archaebacteria, Methylobacteria, Pseudomonas have been found to synthesize PHA to varying levels. Ralstonia eutropha (formerly Alcaligenes eutrophus) has been the subject of much-published research work because it can accumulate PHAs up to 80 per cent dry weight Lee et al. (1996). In this regard, many Bacillus strains have been reported possessing the tremendous potential of PHB accumulation in their cytoplasm under nutrient limiting conditions at a level of $6-97 \%$ of dry cell weight. In this present work, attempts were made to characterize the PHB extracted from Bacillus siamensis

\section{Detection by TLC:}

The Chromatography Chamber was saturated with solvent system. The extracted PHB were dissolved in chloroform and spotted on TLC plate by capillary. The plate is carefully placed in a saturated chromatography jar and allowed to run. When the mobile phase reached 3/4th length, the plate was taken out and air-dried. Then, the TLC plate was exposed to iodine vapours. After a few minutes, brown coloured spot were observed which indicated the presence of lipids. Similar observations were made by Brigham et al. (2010). PHAs are primarily linear, head-totail polyesters composed of 3-hydroxy fatty acid 
monomers Madison and Huisman (1999]. Hence, from TLC, presence of lipids by the brown spot indicated the granules of PHB present in the bacterial strain.

\section{GC-MS analysis:}

Mostly the microorganisms accumulate either scl-PHA's with 3HB units or mcl- PHA's containing 3Hydroxyoctate and 3hydroxydecanate as the major monomers. The major peak at 12.73 retention time represents the presence of 3-PHA. This retention time is on par with the results of Okwuobi et al, 2013. The peak at the retention time 3.8 depicted the presence of Octadecanodic acid which is the characteristic feature of PHB. Similar results were observed by Nurbas and Kutsal (2004). Kim et al . 2012 also referred to the same for the extracted PHB. The results of Bhuwal, et al. (2013), represented the presence of hexadenoic acid matches with the peak at the RT of 11.6 is matched with our retention peak at 11.8. Similarly the peaks at $12.792,13.75$ represent the tetradeconic acid and methyl ester respectively. And the monomers of the polyester family compounds were matched with the peaks at 13.75 and 15.72 . The presence of ethyl, trimethyl groups shows the presence of many monomers, thereby providing crude polymer production.

\section{FTIR}

Data interpretation is in the form of stretching and bending of the peaks for the concerning compound i.e. PHB. The extracted PHB from Bacillus siamensis PHB01 was subjected to FT-IR analysis to find out the various functional groups that represent the signal peaks of PHB. Extracted PHB was subjected to IR analysis and absorption spectrum was recorded in the wavenumber range i.e. $4000 \mathrm{~cm}^{-1}$ to $400 \mathrm{~cm}^{-1}$ using a single beam spectrophotometer. The absorption spectra of the PHB from Bacillus siamensis PHB01 are shown in Fig. The absorption peak at wave number $3274 \mathrm{~cm}-1$ represents hydroxyl group ($\mathrm{OH})$. Peaks at wavenumbers $2923 \mathrm{~cm}-1,2954 \mathrm{~cm}-1$ correspond to methylene group. The peaks at wave numbers $1526 \mathrm{~cm}-1,1623 \mathrm{~cm}-1$ and $2339 \mathrm{~cm}-1$ correspond to $(-\mathrm{C}=\mathrm{C}-)$ stretch, $(\mathrm{N}-0)$ asymmetric stretch and $(-\mathrm{C} \equiv \mathrm{C}-)$ stretch respectively. The peaks at wave numbers $1376 \mathrm{~cm}-1,1450 \mathrm{~cm}-1$, indicate $\mathrm{CH}$ vibrations of methyl $(-\mathrm{CH} 3)$ and methylene $(-\mathrm{CH} 2)$ groups. The absorption peaks at wave numbers $500-$ $1000 \mathrm{~cm}-1,1055 \mathrm{~cm}-1$ and $1230 \mathrm{~cm}-1$ denote $(\mathrm{OH})$ group, $(\mathrm{C}-0)$ stretch and $(\mathrm{C}=0)$ ester group. The FT-IR analysis of PHB extracted from the isolate PHB01 correlated with the reports of Taran (2011) and standard.

The extracted polymer show peak at the wavelength of $2927.41 \mathrm{~cm}^{-1}, 1453.1 \mathrm{~cm}^{-1}, 1377.89 \mathrm{~cm}^{-1} 1242.9$ $\mathrm{cm}^{-1}$ corresponding to specific rotations around carbon atoms specific to certain functional groups. The peak at $1242.9 \mathrm{~cm}^{-1}$ corresponds to $-\mathrm{CH}$ group. Similar results were obtained in Pseudomonas putida by Asheeba et al. (2013). The peak at 1242.9 indicates the $\mathrm{C}-\mathrm{O}-\mathrm{C}$ group and it is on par with the results of Nygaard et al. (2019). The presence of functional groups like $\mathrm{CH}_{2}, \mathrm{CH}, \mathrm{C}=\mathrm{O}$ and $-\mathrm{OH}$ present in the sample PHB01 revealed the character of extracted PHB. Pradhan Shreema, 2014 also obtained similar results. The methionine group $(\mathrm{CH})$ gave a strong bond in the range of $1300-1400 \mathrm{~cm}^{-1}$ and 2900 to $3000^{\mathrm{cm}-1}$ respectively. These frequencies values $29.27 .41,1453.1,1377.89 \mathrm{~cm}^{-1}$ were higher than the 
normal values because of the polymerization. The carbonyl group $(C=0)$ gave a strong bond in the range of $1636-1673 \mathrm{~cm}^{-1}$ where the extracted PHB showed the peak at $1640.16 \mathrm{~cm}^{-1}$ Varda et al. (2014).

The $\mathrm{C}-\mathrm{O}$ group showed strong and broad absorption in the range of $1047-1089 \mathrm{~cm}^{-1}$. Here the strong and broad absorption was observed at $1076.08 \mathrm{~cm}^{-1}$. The $\mathrm{C}-\mathrm{H}$ stretch bonds in the polyester were assigned to the bands located in the spectral region around $2900 \mathrm{~cm}^{-1}$. The obtained FTIR absorption peaks from the culture Bacillus siamemsis PHB01 are in agreement with the corresponding spectra to commercial PHB. Based on the above results, it was concluded that the extracted compound from the isolate PHB01 showed be PHB. Similar results were obtained in the bacteria Cuprivirudus necator ATCC 17697 Nygaard et al. (2019). The polymer accumulated in the cytoplasm of the PHB01 in the form of granules showed an FTIR spectrum corresponding to the previous studies.

\section{Conclusion And Future Approach}

Bacillus siamensis PHB 01 is capable of producing PHB. Thus by utilizing the optimum culture conditions we can solve the problems of the high cost of PHB production. To deal with ever-increasing plastic pollution, PHB from bacterial sources using renewable carbon is the better alternative. In this research, PHB produced by Bacillus sp. PHB01 is crystalline in nature and biodegradable. PHB produced by the bacterial system is brittle and breaks easily. Thus, blending PHB with other polymers in an economic way improves its mechanical properties. In both ways the use of starchy material as a carbon source for PHB production and polymer for blending.

\section{Declarations}

\section{Authors contribution:}

All the authors contributed to the study conception and design. Material preparation, data collection and analysis were performed by Subasri, Mani , Gomathi Velu and Kavitha Mary Jackson. The first draft of the manuscript was written by Subasri Mani, Gomathi Velu and Kavitha Mary Jackson were rewritten the manuscript. All authors commented on previous versions of the manuscript. All authors read and approved the final manuscript.

\section{Conflict of interest:}

The authors have no conflict of interest.

\section{Funding:}

No funds, grants or other support was received

\section{References}


1. Ahmed MJ, Murtaza G, Mehmood A \& Bhatti T M (2015) Green synthesis of silver nanoparticles using leaves extract of Skimmia laureola: characterization and antibacterial activity. Materials Letters, 153, 10-13.

2. Alias Z, \& Tan IK (2005) Isolation of palm oil-utilising, polyhydroxyalkanoate (PHA)-producing bacteria by an enrichment technique. Bioresource technology, 96(11), 1229-1234.

3. Anbukarasu P, Martínez-Tobón DI, Sauvageau D \& Elias AL (2017) A diffraction-based degradation sensor for polymer thin films. Polymer Degradation and Stability, 142, 102-110.

4. Arun A, Arthi R, Shanmugabalaji V, Eyini M (2009) Microbial production of poly- $\beta$-hydroxybutyrate by marine microbes isolated from various marine environments. Bioresource technology, 100(7), 23202323.

5. Asheeba S T, Nithya V, Raman MD, Begum TS, Lakshmi M V, Kumar DS. (2013). KEYWORDS PHA.

6. Bhuwal AK, Singh G, Aggarwal NK, Goyal V, Yadav A (2013) Isolation and screening of polyhydroxyalkanoates producing bacteria from pulp, paper, and cardboard industry wastes. International journal of biomaterials, 2013.

7. Brigham CJ, Budde CF, Holder JW, Zeng Q, Mahan AE, Rha C, Sinskey AJ (2010) Elucidation of $\beta$ oxidation pathways in Ralstonia eutropha $\mathrm{H} 16$ by examination of global gene expression. Journal of bacteriology, 192(20), 5454-5464.

8. Burdon KL (1946) Fatty material in bacteria and fungi revealed by staining dried, fixed slide preparations. Journal of bacteriology, 52(6), 665.

9. Burdon KL, Stokes JC, Kimbrough CE (1942) Studies of the common aerobic spore-forming bacilli: I. Staining for fat with Sudan Black B-safranin. Journal of bacteriology, 43(6), 717.

10. Full TD, Jung DO, Madigan MT (2006) Production of poly- $\beta$-hydroxyalkanoates from soy molasses oligosaccharides by new, rapidly growing Bacillus species. Letters in applied microbiology, 43(4), 377-384.

11. Gerhardt P, Murray RGE, Costilow RN, Nester EW, Wood WA, Krieg NR, Phillips GB (1981) Manual of methods for general bacteriology.

12. Juan ML, Gonzalez LW, Walker GC (1998) A Novel Screening Method for Isolating Exopolysaccharide deficient Mutants. Applied and Environmental Microbiology 64, 4600-4602.

13. Kaynar P, Beyatli Y (2009) Determination of poly- $\beta$-hydroxybutyrate production by Bacillus spp. isolated from the intestines of various fishes. Fisheries Science, 75(2), 439-443.

14. Kim MS, Kim DH, Cha J, \& Lee JK (2012) Effect of carbon and nitrogen sources on photofermentative $\mathrm{H} 2$ production associated with nitrogenase, uptake hydrogenase activity, and $\mathrm{PHB}$ accumulation in Rhodobacter sphaeroides KD131. Bioresource Technology, 116, 179-183.

15. Kumar T, Singh M, Purohit HJ, Kalia VC (2009) Potential of Bacillus sp. to produce polyhydroxybutyrate from biowaste. Journal of applied microbiology, 106(6), 2017-2023.

16. Lee IY, Kim MK, Park YH, Lee SY (1996) Regulatory effects of cellular nicotinamide nucleotides and enzyme activities on poly (3-hydroxybutyrate) synthesis in recombinant Escherichia coli. 
Biotechnology and bioengineering, 52(6), 707-712.

17. Liu C, Wang H, Xing W, Wei L (2013) Composition diversity and nutrition conditions for accumulation of polyhydroxyalkanoate (PHA) in a bacterial community from activated sludge. Applied microbiology and biotechnology, 97(21), 9377-9387.

18. Madison LL, Huisman GW (1999) Metabolic engineering of poly (3-hydroxyalkanoates): from DNA to plastic. Microbiology and molecular biology reviews, 63(1), 21-53.

19. Mohapatra S, Mohanta PR, Sarkar B, Daware A, Kumar C, Samantaray DP (2017) Production of polyhydroxyalkanoates (PHAs) by Bacillus strain isolated from waste water and its biochemical characterization. Proceedings of the National Academy of Sciences, India Section B: Biological Sciences, 87(2), 459-466.

20. Nurbas M, Kutsal T (2004) Production of PHB and P (HB-co-HV) biopolymers by using Alcaligenes eutrophus.

21. Nygaard D, Yashchuk O, Hermida ÉB (2019) Evaluation of culture medium on poly (3hydroxybutyrate) production by Cupriavidus necator ATCC 17697: application of the response surface methodology. Heliyon, 5(3), e01374.

22. Okwuobi PN, Ogunjobi AA (2013) Production and analysis of polyhydroxyalkanoate (PHA) by Bacillus megaterium using pure carbon substrates. World Applied Sciences Journal, 28(9), 13361340.

23. Ostle AG, Holt JG (1982) Nile blue A as a fluorescent stain for poly-beta-hydroxybutyrate. Applied and environmental microbiology, 44(1), 238-241

24. Otari SV, Ghosh JS (2009) Production and characterization of the polymer polyhydroxy butyrate-copolyhydroxy valerate by Bacillus megaterium NCIM 2475. Current Research Journal of Biological Sciences, 1(2), 23-26.

25. Panda B, Sharma L, Singh AK, Mallick N (2008) Thin layer chromatographic detection of poly- $\beta$ hydroxybutyrate (PHB) and poly- $\beta$-hydroxyvalerate (PHV) in cyanobacteria.

26. Pradhan, S. H. R. E. E. M. A. (2014) Optimization and characterization of bioplastic produced by Bacillus cereus SE1 (Doctoral dissertation).

27. Rajendran, A, Barik RC, Natarajan D, Kiran MS, Pattanayak, DK (2014) Synthesis, phase stability of hydroxyapatite-silver composite with antimicrobial activity and cytocompatability. Ceramics International, 40(7), 10831-10838.

28. Reddy SV, Thirumala M, Mahmood SK (2009) Production of PHB and P (3HB-co-3HV) biopolymers by Bacillus megaterium strain OU303A isolated from municipal sewage sludge. World Journal of Microbiology and Biotechnology, 25(3), 391-397.

29. Reshma P, Sonal S,Vatsala S (2017) Screening and isolation of polyhydroxy butyrate producers. International Journal for Research in Applied Science and Engineering Technology, 5(12), 1259-1264.

30. Subasri, M.; Gomathi V, and Mary, J. K. (2021). Isolation, Screening and characterization of Bioplastic (Poly Hydroxy Butyrate) producing Bacteria from Termite Mound Soil. Biological Forum An International Journal, 13(4): 923-927. 
31. Taran M (2011) Utilization of petrochemical wastewater for the production of poly (3hydroxybutyrate) by Haloarcula sp. IRU1. Journal of hazardous materials, 188(1-3), 26-28.

32. Varda M, Nishith D, Darshan M (2014) Production and evaluation of microbial plastic for its degradation capabilities. Journal of Environmental Research And Development, 8(4), 934.

33. Yüksekdağ ZN, Aslim B, Beyatli Y, Mercan N (2004) Effect of carbon and nitrogen sources and incubation times on poly-beta-hydroxybutyrate (PHB) synthesis by Bacillus subtilis 25 and Bacillus megaterium 12. African Journal of Biotechnology, 3(1), 63-66.

\section{Tables}

Table 1: Common Properties of PHB (modified from Park et al., 2001)

\begin{tabular}{|l|l|}
\hline Water Insoluble & Soluble in Chlorinated Hydrocarbons Chloroform \\
\hline Good Oxygen Permeability & Relatively Resistant to Hydrolytic Degradation \\
\hline Susceptible To Acids And Bases & Resistant to Ultra Violet \\
\hline Non-Toxic & Biocompatible \\
\hline High Tensile Strength (40mpa) & Melting Point of $179{ }^{\circ} \mathrm{C}$ \\
\hline Extremely Crystalline (80\%) & Thermoplastic Process Ability \\
\hline $\begin{array}{l}\text { Curvature coefficient } \\
\text { (Young) (GPa) - (4-3.5) }\end{array}$ & Density g/cm^3 $(1.25-1.23)$ \\
\hline $\begin{array}{l}\text { Glass transition } \\
\text { Temperature (15-10) }\end{array}$ & $\begin{array}{l}\text { Molecular weight } \\
\text { M.wt. (Dalton) }-{ }^{5} 10 \times 8-1\end{array}$ \\
\hline
\end{tabular}

Table 2 : Nutrient Agar Media

\begin{tabular}{|l|l|}
\hline Components & $\mathrm{g} / \mathrm{L}$ \\
\hline Peptone & 5.0 \\
\hline Sodium Chloride & 5.0 \\
\hline Beef Extract & 1.5 \\
\hline Yeast Extract & 1.5 \\
\hline Agar & 20 \\
\hline Distilled Water & $1000 \mathrm{~mL}$ \\
\hline $\mathrm{pH}$ & $7.4 \pm 0.2$ \\
\hline
\end{tabular}

Table 3: GC- MS Analysis Report 


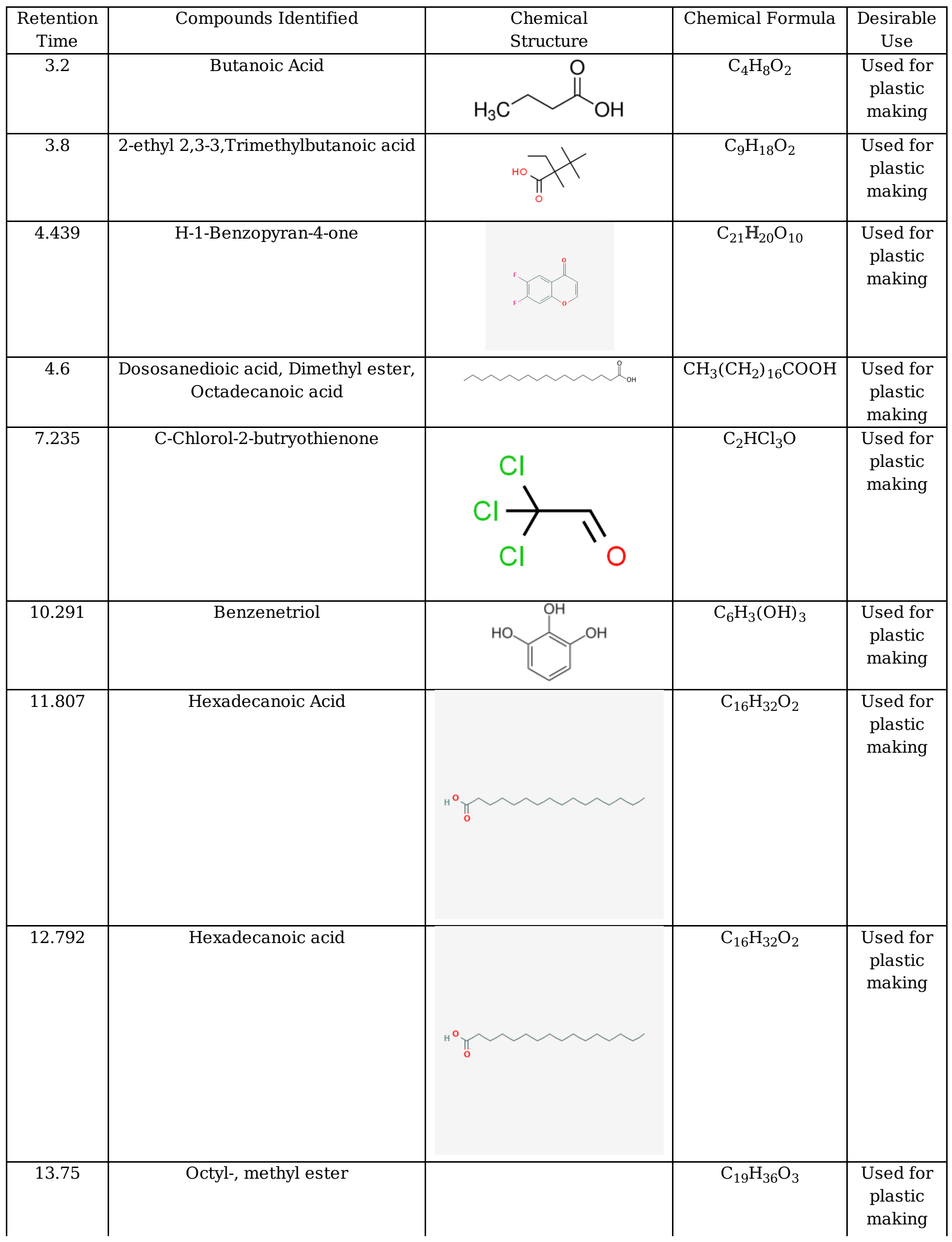




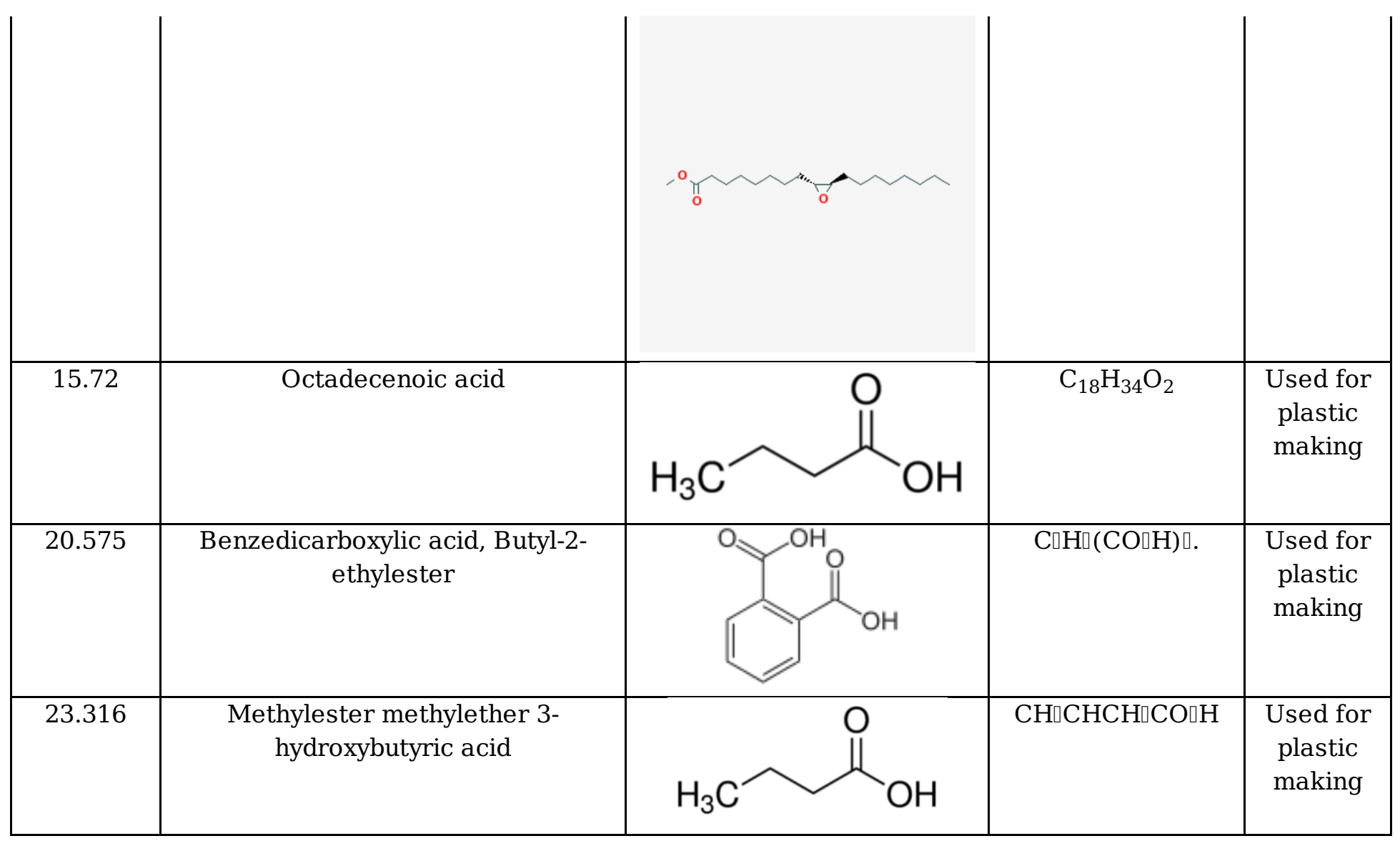

\section{Table 4: IR spectrum of sample}

\begin{tabular}{|c|c|c|c|}
\hline Characteristic peaks $\mathrm{cm}^{-1}$ of Extracted PHB & Reference Peaks & Intensity & Description \\
\hline 2927.41 & $\sim 2900$ & Strong & C-H Vibration \\
\hline 1640.16 & 1635 & Strong & Carbonyl group (C=O) \\
\hline 1453.1 & 1457 & Strong & CH3 Asymmetric deformation \\
\hline 1377.89 & 1379 & Strong & CH Symmetric deformation \\
\hline 1242.9 & 1276 & Strong & CH group \\
\hline 1076.08 & 1076 & Strong & Ester group (C-O) \\
\hline 1022.09 & 1029 & Strong & C-O polymeric group \\
\hline 495 & 491 & Strong & Alkyl Halides \\
\hline
\end{tabular}

\section{Figures}




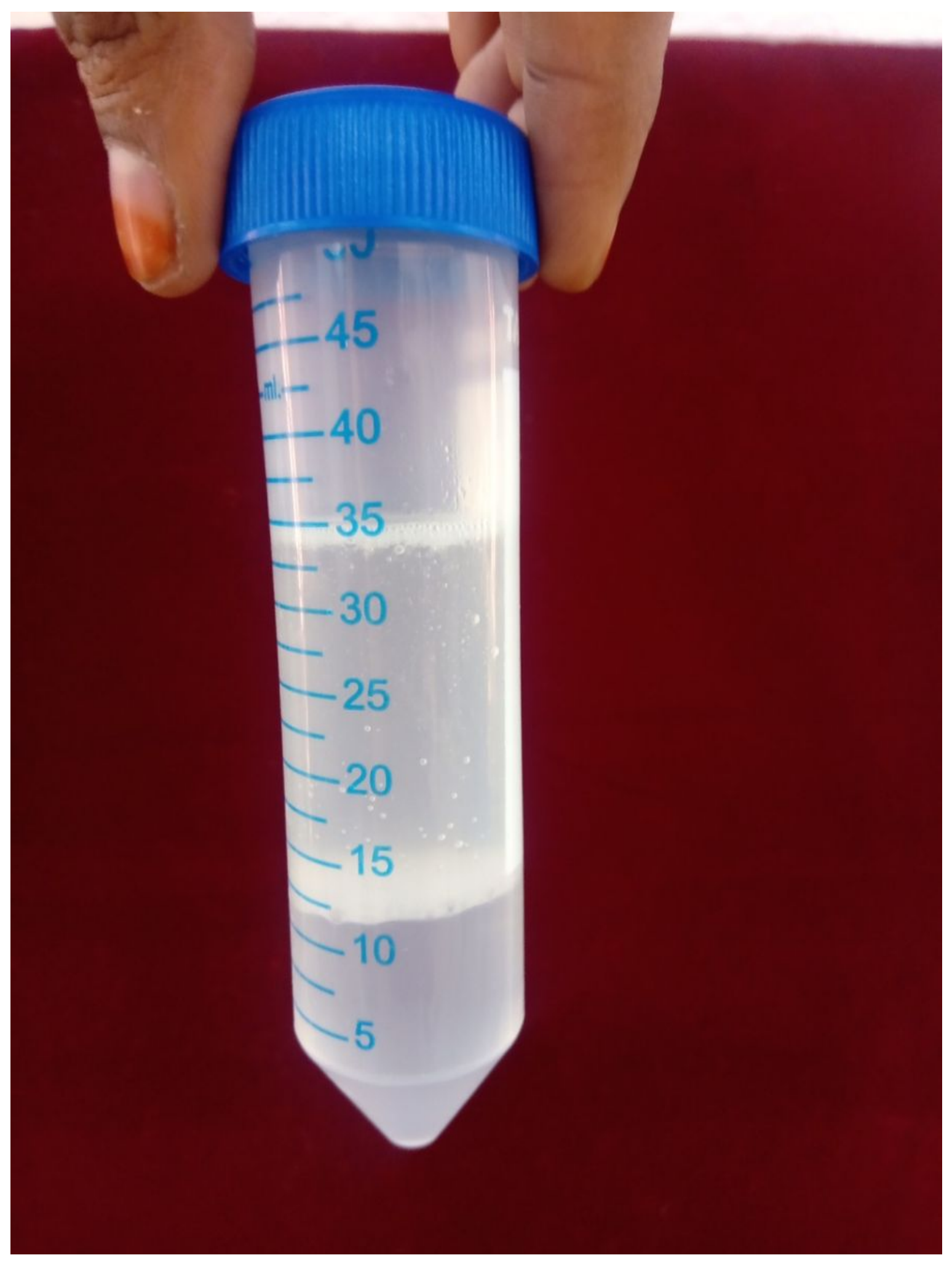

Figure 1

Extraction of PHB 


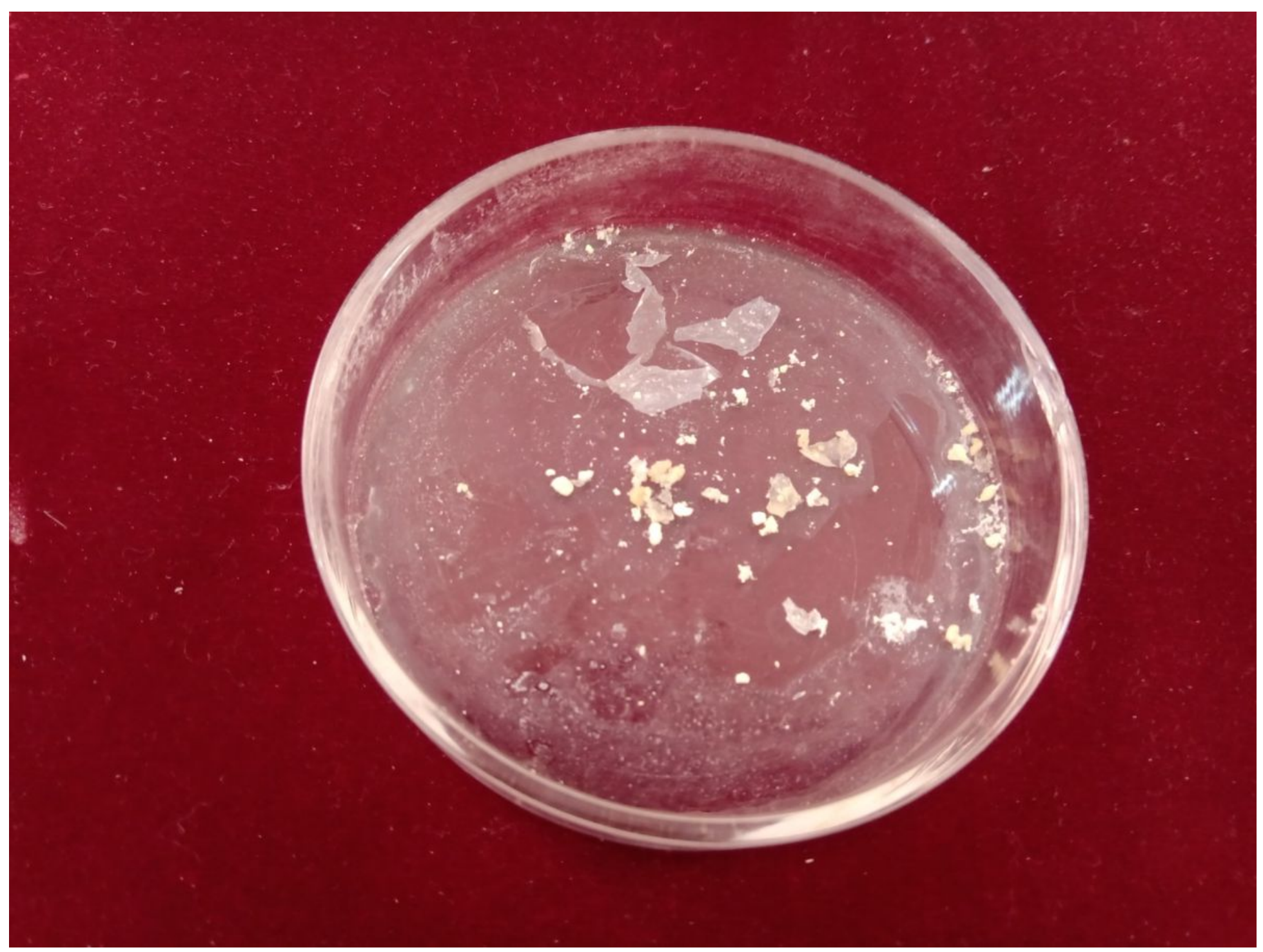

Figure 2

Extracted PHB 

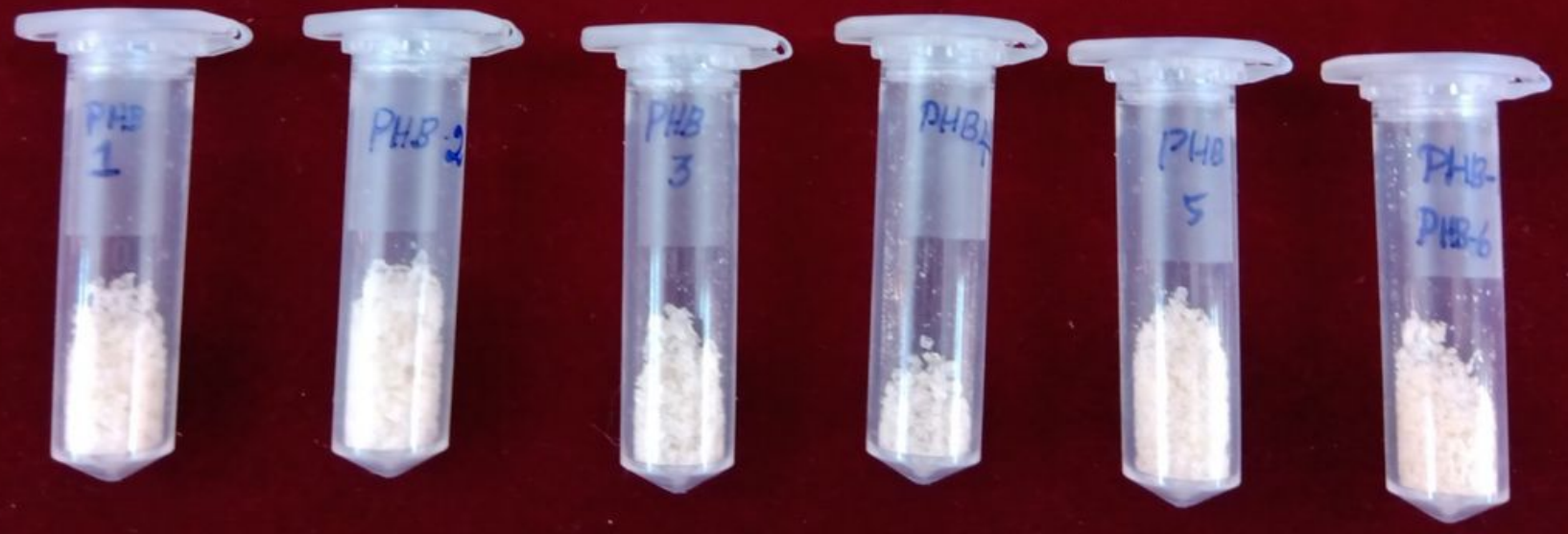

Figure 3

Extracted PHB used for analysis 


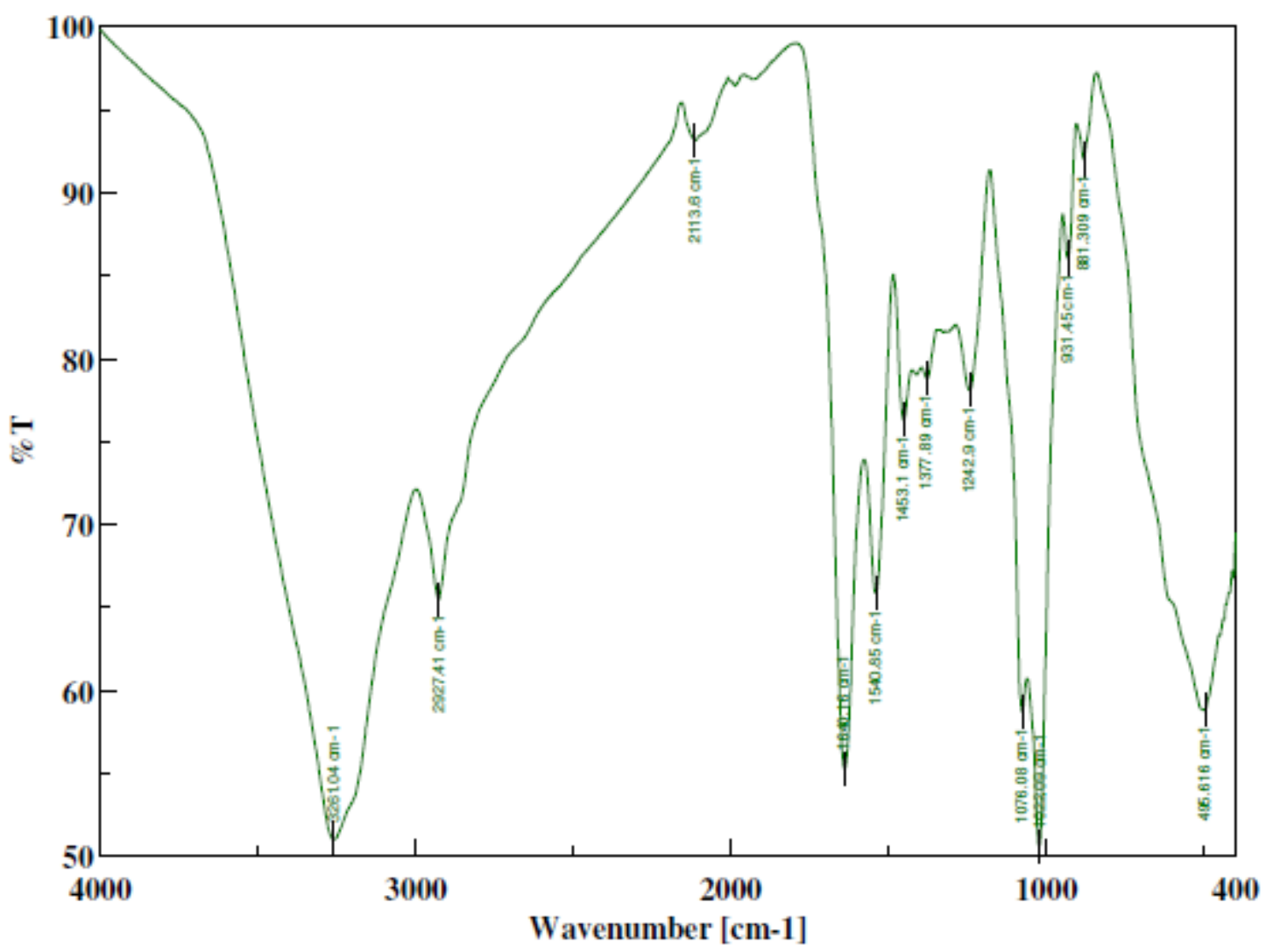

Figure 4

FTIR spectrum 
User

Division

Company

TNAU

$\begin{array}{ll}\begin{array}{ll}\text { Measurement Information] } \\ \text { Model Name }\end{array} & \text { FT/IR-6800typeA } \\ \text { Serial Number } & \text { A001661794 } \\ \text { Measurement Date } & 3 / 10 / 20214: 41 \text { PM } \\ & \\ \text { Light Source } & \text { Standard } \\ \text { Detector } & \text { TGS } \\ \text { Accumulation } & 15 \\ \text { Resolution } & 4 \mathrm{~cm}-1 \\ \text { Zero Filling } & \text { On } \\ \text { Apodization } & \text { Cosine } \\ \text { Gain } & \text { Auto }(8) \\ \text { Aperture } & \text { Auto }(7.1 \mathrm{~mm}) \\ \text { Scanning Speed } & \text { Auto }(2 \mathrm{~mm} / \mathrm{sec}) \\ \text { Filter } & \text { Auto }(10000 \mathrm{~Hz})\end{array}$

[Detailed Information]

Creation date 3/10/2021 4:43 PM

Data array type Linear data array

Horizontal axis Wavenumber $[\mathrm{cm}-1]$

$\begin{array}{ll}\text { Horizontal axis } & \text { WT } \\ \text { Vertical axis } & \end{array}$

$\begin{array}{ll}\text { Vertical axis } & \% \mathrm{~T} \\ \text { Start } & 349.053 \mathrm{~cm}-1\end{array}$

End $\quad 4000.6 \mathrm{~cm}^{-1}$

Data interval $\quad 0.964233 \mathrm{~cm}-1$

Data points $\quad 3788$

\section{TAMILNADU AGRICULTURAL UNIVERSITY - AGRICULTURAL MICROBIOLOGY}

INSTRUMENT : PERKIN ELMER CLARUS SQBC
INJECTION :1 MICRO LITER
SAMPLE ID :SAMPLE-15 0503
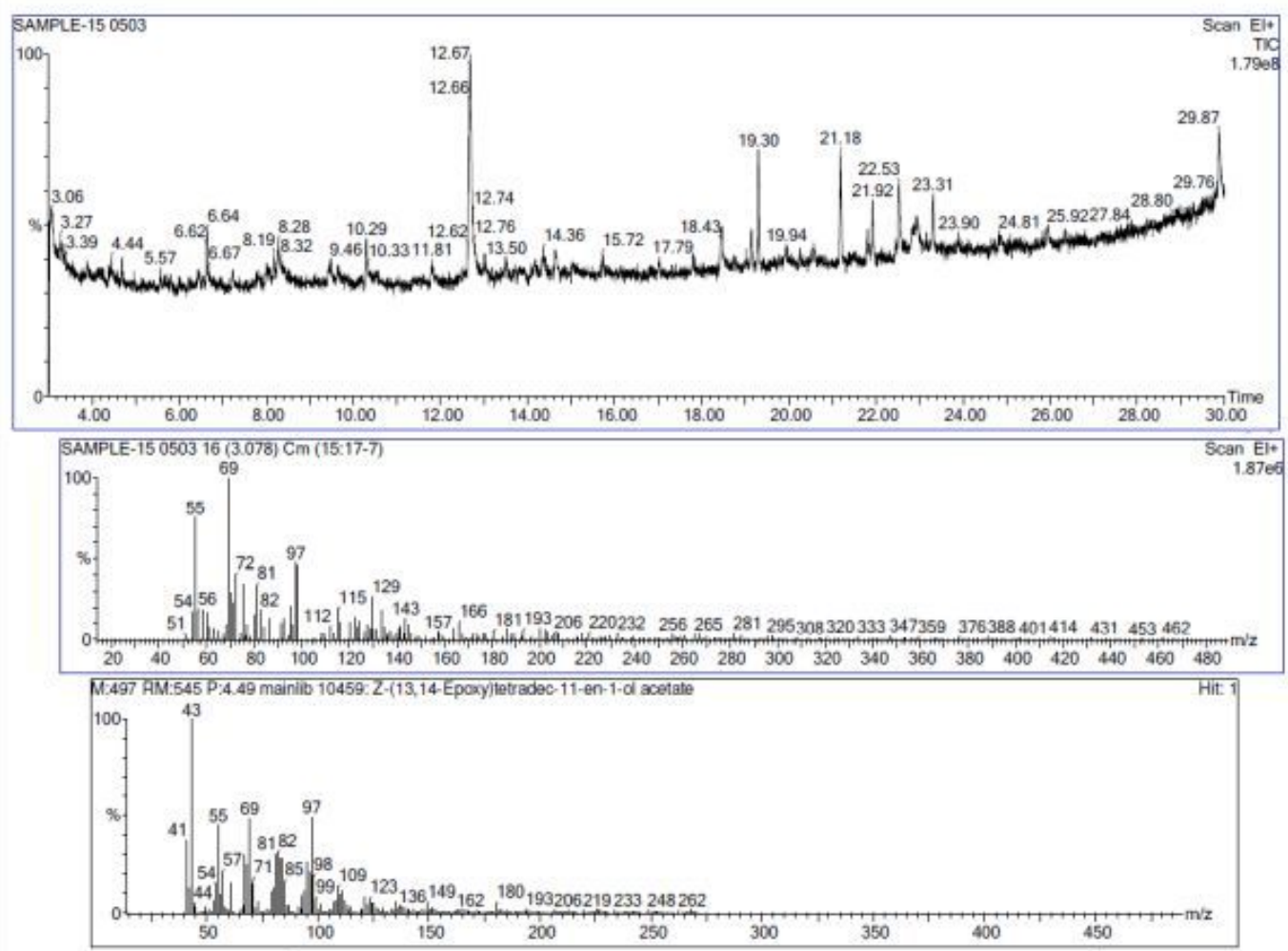

\section{Figure 5}

GC-MS spectrum 


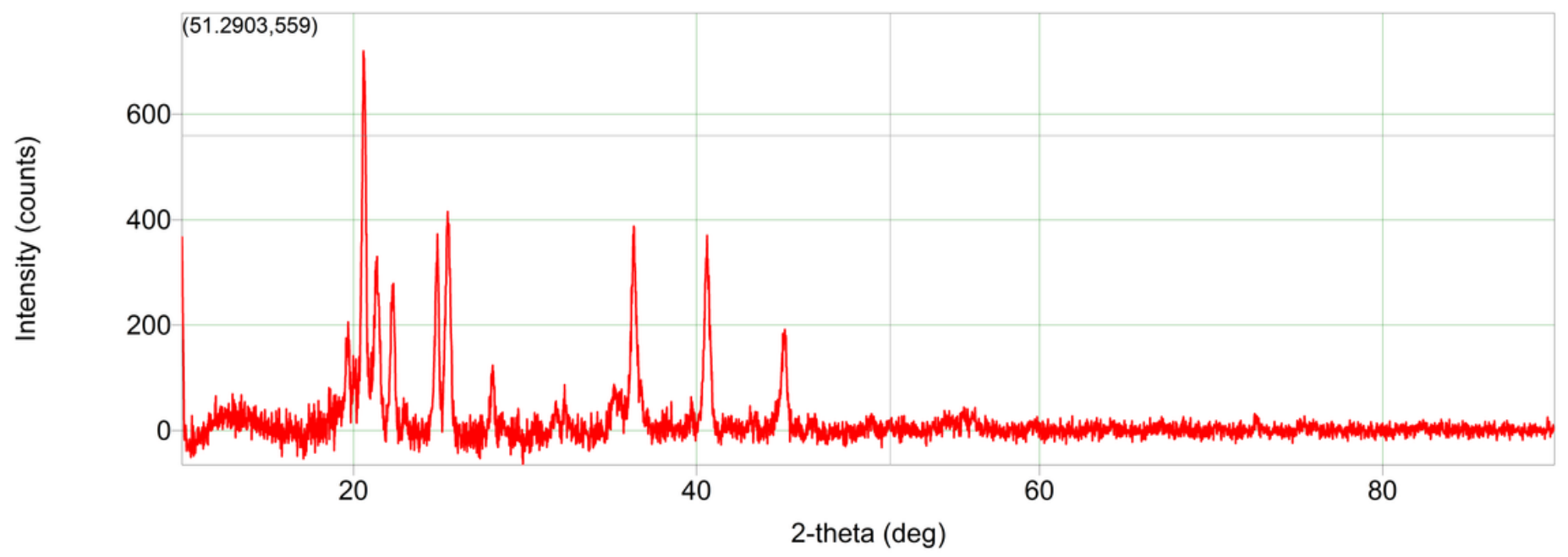

Figure 6

XRD Graph 